\title{
INSERÇÃO DO PROFANO NO SAGRADO - a adoração do menino num corpus de peças de Cante
}

Maria José Albarran Carvalho*

RESUMO: Sob enfoque essencialmente semântico, analisa-se um corpus composto por variantes de cante sagrado. Uma análise da referência nominal ao Menino, num mundo de crenças cristãs, contrasta formas de instanciação do divino. Como objecto abstracto complexo, aquele é referido por nomes próprios e tanto por nomes comuns abstractos como concretos. Estes processos de referência aproximam o sagrado do homem, ocultando-o na capa de entidades mais vizinhas, as quais se manifestam, no nível frásico e transfrásico, em elementos, avulsamente tratados, como sejam: alguns predicadores, particularidades lexicais, morfológicas e fonológicas; casos, também pontuais, de ordem marcadamente sociolinguística e textual. Todos confluem na profanização do sagrado que o artigo tem por objectivo caracterizar.

Palavras-chave: semântica nominal, semântica verbal, propriedades prototípicas, propriedades episódicas, nível frásico, nível transfrásico.

\section{BREVE INTRODUÇÃO LINGUÍSTICA}

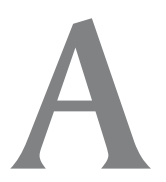

exposição que se segue pauta-se por uma perspectivação linguística de enfoque sobretudo semântico - teoria de G. Carlson (1977; 1982; 1989). Incidindo, neste caso, sobre os chamados Sintagmas Nominais $(\mathrm{SN})$ genéricos, analisa-se, simplificada e brevemente, o tratamento dado em trabalho recente daquele linguista a entidades de abstracção complexa. Contudo, a análise visa, principalmente, um enquadramento no mosaico cultural de temas que convergem na Adoração do Menino. No tecer desta óptica, o exame linguístico recorre não só à classe de palavras eleita, mas também à dos verbos, e, ainda, a outras componentes da gramá-

Projecto Interdisciplinar 0 Cante ... Escola Superior de Educação de Beja. 
CARVALHO, Maria José Albarran. Inserção do profano no sagrado - a adoração do menino num corpus de peças de Cante.

tica, v.g.: lexical, morfológica, fonológica, além de roçar níveis transfrásicos de análise.

O corpus considerado corresponde a 100 variantes de 5 peças de Cante sagrado ${ }^{1}$, recolhidas por A. Cartageno (1973-1983) ou editadas em audiograma / CD e que versam o tópico do divino, do sagrado, mais concretamente, num universo cristão, o do Menino. Examina-se a genericidade nominal na referência às manifestações do sagrado, contrastando-a com referências profanas paralelas, via referência nominal concreta, para destaque da apropriação do divino pela realidade temporal - aliada à função de $\mathrm{N}$ próprios - visível e, portanto, mais próxima. Os predicadores - tipo de verbo e respectivo valor temporal e aspectual - são observados no mesmo sentido.

Qualquer utente do português reconhece na frase (F) 1 um SN que denota, globalmente, uma espécie, i.e. algo genérico. Ou seja, de modo geral, é-lhe atribuída, como caracterizadora do objecto de referência, uma propriedade intemporal e incondicionalmente predicada, sem individualização alguma:

(1) A rosa é perfumada (é típico da espécie ter tal propriedade, mesmo se houver excepções)

$\mathbf{O}$ cão é fiel (idem)

Aplicando ao português a teoria de G. Carlson, A. C. Lopes (1993) procura desvendar diferentes tipos de $\mathrm{SN}$ genéricos atendendo aos referentes. Muito abreviadamente, adoptando G. Carlson (1977), aquela autora considera que o domínio semântico da referência passa a considerar "objectos (denotados por nomes próprios ou por descrições definidas) e espécies ... ambos concebidos como indivíduos atemporais que se 'realizam' através de instâncias ou fases .... ancoradas no tempo e no espaço” (A. C. Lopes, 1993, p. 118-9). A espécie correspondente a cada SN genérico constitui "entidade que pode ter fases múltiplas e simultâneas em localizações distintas, no mesmo mundo" (id, p. 119). De modo similar se procede à tripartição do domínio de interpretação dos predicados que, assim, podem ser exclusivos de nomes genéricos,

Enquadradas aqui como peças de cante, adoptando-se critérios de M. Giacometti e A. Cartageno, entre outros especialistas. 
de objecto ou de fases, consoante deles resulte a aplicação, respectivamente, de propriedades prototípicas disposicionais do conjunto aberto de membros da espécie, de índole estável - objectos - ou transitória - fases - (ib).

No caso vertente, na definição da espécie "terá de ser convocado um feixe de propriedades ... essenciais e comuns a todos os membros que realizam a espécie", as prototípicas, "e ainda propriedades que não se aplicam aos membros", mas apenas a uma entidade "de ordem superior, cuja caracterização implica um maior grau de abstracção e de complexidade conceptual” (c.p.J.Peres, 1993 apud A.C.Lopes, 1993; Heyer, 1988).

Entre os SN genéricos, A.C. Lopes $(1993,120)$ inclui as sequências sintácticas: Determinante (definido / indefinido), Nome (singular / plural) com restrições de ocorrência. Em nenhuma destas sequências é lícito: i) quantificar (ver F2 a), porque isso inviabiliza a significação genérica; ii) submeter o SN à interrogação - QUAL? / - QUAIS? sem desfazer a genericidade (ver F2 b); iii) colocar o SN genérico em posição de Objecto Directo, pois perde o valor de espécie (ver F3); iv) ocorrer o SN genérico em contextos enfático-contrastivos de $\mathrm{F}$ adversativas e concessivas (ver F4). Tais SN aceitam o modificador GERALMENTE (v.g.: F5). Atente-se nos exemplos, assinalados com asterisco quando $\mathrm{F}$ semanticamente, ou de qualquer outra forma, mal formadas:

(2) a) * Uma / Alguma rosa é perfumada

* Um / algum cão é fiel (a quantificação com o numeral ou o determinante indefinido cancela a interpretação genérica)

b) A rosa é perfumada -*Qual rosa?

O cão é fiel

-*Qual cão? (a interrogação impede o sentido genérico)

(3) Ela oferece uma rosa (= uma rosa específica e não a espécie) Ela oferece um cão (idem)

(4) *É uma rosa, mas é perfumada

* É um cão, embora seja fiel (contrasenso por ser específico do SN a propriedade atribuída) 
CARVALHO, Maria José Albarran. Inserção do profano no sagrado - a adoração do menino num corpus de peças de Cante.

(5) Geralmente a rosa é perfumada

Geralmente o cão é fiel

A realidade de as $F(2)$, (3) e (5) exprimirem generalizações invalida as circunstâncias sintácticas nelas exemplificadas e legitima a modalização da F (4), com poucas excepções. Deixando de lado a descrição dos SNs genéricos - que podem ser outros e apresentar mais condicionantes - distinguem-se as F genéricas dos SNs genéricos, pois estes referem espécies por si próprios, podendo ocorrer, consequentemente, tanto em $\mathrm{F}$ genéricas (+ durativas) não espácio - temporalmente delimitadas, como em F episódicas (-durativas) espacial e temporalmente delimitadas. Aquelas encerram valor genérico por asserirem, em intensão, verdades que o são em todos os intervalos de tempo estado habitual e não contingente - em português preferencialmente denotado pelo presente do indicativo.

\section{APLICAÇÃO AO CANTE SAGRADO}

Extrapola-se a análise de A. C. Lopes (1993) para os Nomes (N) abstractos - a autora atinha-se aos N contáveis - e, nesta direcção, Deus, $\mathrm{N}$ próprio, funciona como designador rígido - porque estes útimos denominam univocamente objectos / entidades exclusivos - de objecto abstracto único e de excepcional complexidade conceptual. A natureza deste designador equivale ao acima mencionado referente de ordem superior, que apresenta, desdobrando-se, "fases múltiplas e simultâneas em localizações distintas no mesmo mundo" (id, p. 119) e se submete, exclusivamente, à predicação de propriedades prototípicas (ib). Em contextos de abstração ideológica, este $\mathrm{N}$ próprio de objecto abstracto revela-se, frequentemente, incompatível com a referência do episódico, efémero ${ }^{2}$, contudo, mantém uma natureza diversa das outras entidades que o instanciam, v.g.: Jesus Cristo e revelações diversas

Embora, em várias situações, consoante A. C. Lopes (comunicação pessoal, 1998), o N Deus ocorra em F episódicas, veja-se o exemplo daquela autora "E Deus fez o Homem”, testemunho da integração simbólica do eterno no contingente. 
do Espírito Santo, ambos manifestações do N próprio Deus ${ }^{3}$. Mais distinta, ainda, é essa natureza se confrontada com a de inúmeras potências celestes, intermediárias do profano no divino e viceversa, v.g.: Virgem, Santos, Beatos, etc.

Assim, a teoria, que A. C. Lopes (1993) aplica aos N contáveis do português, revela-se adaptável aos $\mathrm{N}$ abstractos que denominam o sagrado - em equivalência ao divino, a Deus - e aos N abstractos / próprios que remetem para manisfestações daquele. Aos $\mathrm{N}$ concretos ${ }^{4}$, igualmente instanciadores do sagrado, aplicam-se do mesmo modo, porquanto estes remetem para aquele, numa imagem quotidianizada, e contingente, do atemporal.

$\mathrm{O}$ facto é que estes $\mathrm{N}$ apresentam circunstâncias de ocorrência afins das da genericidade, veja-se como a $\mathrm{F}(6)$ se comporta, pelo menos, como as $F(1)$, (2) e (4):

(6) O Menino / A Virgem é a nossa esperança

Na realidade, é prototípico da espécie sagrada assumir tal propriedade. A determinação com UM relega para interpretação de genericidade, numa sinonímia com a definitude, próxima da função do $\mathrm{N}$ próprio. Admite-se a posição de objecto directo, contudo, nalguns contextos, com perda da leitura abstracta, v.g.: Ofereci um menino Jesus / a Virgem (obrigatoriamente uma imagem). Suscita estranheza sob adverbiação com GERALMENTE, apenas por se tratar de caso em que a propriedade disposicional tipificadora da espécie é universalizante. Julga-se que esta referência ao sagrado se situa maioritariamente nos $\mathrm{N}$ de espécie, embora, parcelarmente, também nos designadores rígidos, constituindo referenciação mista.

As peças percorridas remetem, exclusiva ou prevalecentemente, para os subtemas: o Menino Redentor; a Adoração do Menino pelos

\footnotetext{
3 A. C. Lopes (comunicação pessoal, 1998) insiste na natureza semanticamente diversa do $\mathrm{N}$ próprio Deus, objecto abstracto conceptualmente muito complexo, relativamente às entidades referidas como instanciadoras - Jesus Cristo, sobretudo, ao qual se aliam as potências celestes. Estas funcionam, simetricamente, como intermediárias do profano junto de Deus e deste junto do profano.

4 Esta terminologia situa-se na tradição gramatical portuguesa.
} 
CARVALHO, Maria José Albarran. Inserção do profano no sagrado - a adoração do menino num corpus de peças de Cante.

pastores e pelos reis magos; a Humanidade do Menino e o Romance do Menino. Três peças situam-se fora do conjunto quadripartido, confirmando uma linha de inserção do profano no sagrado que este estudo pretende mostrar; contudo, não serão objecto do presente artigo. Centra-se o trabalho na Adoração do Menino, dividida em dois subtemas: pelos pastores ( 65 peças); pelos reis magos ( 35 peças). Ambos se recolhem, quase exclusivamente, no Baixo Alentejo. Incide-se, particularmente sobre o concelho de Serpa e localidades da margem esquerda do Guadiana.

Atém-se o artigo, por outro lado, ao sentido etimológico de sacer, na sua ambiguidade positiva / negativa de denotar "aquilo que é consagrado aos deuses" / "aquilo que suscita horror", visto ligar-se ao sacrifício de vítimas, de acordo com E. Benveniste (trad. 1969, p. 188). Em ambas as abonações se delimita uma fronteira entre o sagrado e o profano. M. Eliade, na mesma via, refere a fundação de espaços sagrados em toda a história da humanidade (trad. 1965, p. 40-1), demarcados, por estarem destinados a manifestações invisíveis, metafísicas, da realidade do nosso mundo, da natureza visível, i.e., profana (id, p. 15). O sagrado fica conotado com o transcendente e o ameaçador, longinquamente superiores. $\mathrm{O}$ ser humano procura referir essa entidade inatingível, e temível, por signos que a avizinham de si, do seu dia-a-dia palpável. O homem fixa-se num pensamento hierofânico, dotado da capacidade de percepção das manifestações do sagrado em objectos vulgares (ib). Assim, aproxima o sagrado do seu real profano, referindo as manifestações daquele por meio deste. $O$ estudo incide sobre uma concepção cristã - a única do corpus - reduzida a conceitos de uma religião natural (A. Cartageno, comunicação pessoal, 1998), a mais disseminada na (re)produção de todo o canto religioso no espaço nacional. Se fossem outros os corpora, haveria que repensar os instrumentos de análise agora utilizados.

Este será o fio condutor que, articulado à óptica linguística, desnuda e fundamenta a análise, adiante exposta, de diferentes designadores rígidos, $\mathrm{N}$ próprios, e de diversos comuns, sobretudo concretos, que instanciam o objecto abstracto complexo da divindade - o N 
próprio Deus. No mesmo sentido são considerados predicadores dispersos, contextos discursivos, de igual modo pouco sistematizados, e outros aspectos linguísticos, sobretudo lexicais e morfofonológicos. Não cabe aqui o inverso, a inserção do sagrado no profano ${ }^{5}$. Deixa-se para estudo de outros, eventualmente do próprio grupo do Projecto.

\section{A ADORAÇÃO DO MENINO PELOS PASTORES}

Como primeira instanciação do $\mathrm{N}$ abstracto do sagrado, espáciotemporalmente realizadora da entidade divina, referida pelo $\mathrm{N}$ próprio de objecto abstracto Deus - a assumir o dom da ubiquidade e da pluralidade de fases num só tempo e mundo - encontra-se Deus Menino (também Menino Deus) que ocorre 52 vezes. É a superior entidade, manifestação da abstracção / espécie do sagrado, instanciadora do próprio Deus, que se apresenta em fases reveladoras dessa mesma divindade. Surge, numa ordenação quantitativamente descendente, sob outras designações: Menino (54), Jesus (13), Menino Jesus (8), Redentor (7), Doce Jesus (6), Meu Menino Jesus e Senhor (5), Menino Belo, Meu Menino da minha alma e fruto esperado / tão desejado (2), Menino de Maria, Pão da vida, Espiga, Rei dos Reis e filho meu (1). Todas estas referências desfazem o valor de espécie, profanizando-se, pelo contingente, o sagrado.

$\mathrm{O}$ arquétipo divino surge, directamente, nos $\mathrm{N}$ próprios - se bem que diversificados, pela imposição da maiúscula em contexto situacional cristão, são claramente designadores de Deus -, decrescentemente seriados: Deus (4), Deus do céu (3), Rei do céu, Rei dos monarcas e Meu Sacramento Divino (2), O Divino, e Santíssimo Sacramento (1). São as referências menos frequentes no corpus e cerca de metade das quais realiza-se por N concretos, rei, monarca. As sequências nominais "a roseira do sacrário dá boa rama" (2) "a rosa na tribuna" e a "rama na tribuna" (1) recobrem a mesma entidade superordenada, em $\mathrm{N}$ concretos.

Foi A. Cartageno quem chamou a atenção para a perspectiva recíproca daquela que aqui se adoptou. 
CARVALHO, Maria José Albarran. Inserção do profano no sagrado - a adoração do menino num corpus de peças de Cante.

Numa segunda instanciação da abstracção sagrada encontramse intermediários do profano junto do sagrado - outras potências celestes: à cabeça, a Virgem (4) também denominada: Maria (11), Virgem Pura, Senhora e Virgem Maria (3), Vossa Mãe, Mãe Santa e Virgem sagrada (2). Sucede-lhe S. José (1), designado, ainda, por: José (8) e vosso pai (2). Seguem-se: a Estrela Luzente (4), os anjos (3), os três reis (2), Santa Ana (1) e Santa Madalena (1). Esta série afasta-se, ainda mais, do $\mathrm{N}$ de objecto abstracto Deus e da espécie sagrada, humanizando-a no quotidiano do mundo e do tempo.

Com a listagem pretende-se provar a preferência por designações menos teológicas ou bíblicas e mais vizinhas do homem. Para o caso das realizações do divino ilustra-se com os $\mathrm{N}$ próprios Menino, Menino de Maria, Menino Belo, Meu Menino da minha alma. Para os intercessores junto do sagrado, a Virgem sobressai mas, sobretudo, quando se lhe apela pelo $\mathrm{N}$ próprio Maria. Tanto a referência a esta como a S. José e a Santa Ana alternam com o léxico do parentesco, v.g.: vossa mãe / vosso pai e até seu avô.

$\mathrm{Na}$ definição do espaço relacionado com o divino, ocorrem $\mathrm{N}$ topónimos e N comuns: Belém (7), o tronco da sagrada árvore genealógica (6) e altar (1) contra porta(s) da igreja (4) e portal(ais) sagrado(s) em comutação com portais adentro (25). E, na especificação de um tempo sagrado, as referências nominais circunscrevem-se a noite de Natal (7) e a noite de santa alegria (1). São em igual número as referências espáciotemporais profanas: sobre palhinhas deitado (24), na neve (21), cabana (5), ao rigor do caramelo (2) e palácio real (1) - predominantemente bíblicas, são evocadoras, contudo, da tradição narrativa (catequese e liturgia) tanto como da dramática ${ }^{7}$, divulgada pelo clero - presépios de Serpa

6 Já era, porém, uma designação bíblica, mantida na liturgia (A. Cartageno, comunicação pessoal, 1998); tratando-se, portanto, de importação - do próprio texto dos Evangelhos - do processo de profanização em análise, embora muito mais desenvolvido no corpus considerado.

7 No Alentejo, no início do século, segundo J. Vasconcelos (1938, p. 878nt2), ainda andava “... de casa em casa uma espécie de companhia teatral ambulante, formada por gente pobre da terra, a qual, para obter algumas esmolas, representava a scena do nascimento, fazendo um de Nossa Senhora, outro de S. José, outro de Anjo, outro de preto, etc ... 
entre mais localidades. A. Marvão (1997) afirma que os cantes do Menino e dos Reis eram cantados na Igreja, pelo povo, depois da Missa da Meia-Noite, visto que "os cantes próprios da Missa, quando os havia, eram litúrgicos, faziam parte daquela e eram em Latim, idioma que o povo desconhecia" (Id, p. 176). Uma das principais formas de apropriação do culto, pelo povo, foi a língua portuguesa. Em seguida vinha o uso com que no desempenho linguístico, a maioria rural baixo alentejana exprimia o seu vínculo ao sagrado - dialectal, arcaizante e socialmente marcado. O povo criou "uma liturgia paralela", consoante A. Cartageno (1997).

Mantendo o estudo nas expressões nominais, vejam-se as profusas referências profanas a objectos, propriedades, relações atribuídas ao Menino. Procede-se, aponte-se, num sentido lato, considerando que a adjectivação, por constituir modificação do substantivo, se pode integrar na referência nominal. O Menino recebe camisinhas de Bretanhatecido fino de linho ou algodão, usado também em toalhas a partir do século XV (J. P. Machado, 1977v I, p. 463) -, botanitos de cristal, o fato verde, sapatinhos da Feira de S. André (Anexo, 1), admitindo-se porfia na oferta das solas e dos saltinhos, galão ou fita para o chapéu, leite e mimo porque é pequenino... ${ }^{8} \mathrm{O}$ Menino é caracterizado pela boquinha de pão $e$ leite, é belo e lindo como qualquer outro menino.

outras vezes armava-se em casa, particularmente, um presépio ... e não faltava a cigana do Egipto que cantava. "Sou cigana do Egipto, / Caminhando para Belém / Dar graças ao Menino / E à Virgem parabém / Glória a Deus, glória a Deus / Glória a Deus nas alturas, / Na terra paz aos homens, / Que são suas criaturas". Na verdade, as festas do nascimento têm lugar desde a Idade Média. Os vilancicos cantados, em autos de Natal - muito comuns nos séculos XVI-XVII - ou de qualquer modo por ocasião desta festa, sobre a infância de Jesus, desenvolvem-se a partir dos séculos indicados, aproximando-se muito das canções de berço, numa intersecção profano-sagrado-profano.

8 J. Vasconcelos (1938, p. 886-7) remete para duas canções, uma alemã e uma valónica, em que, respectivamente, o pai vai para o bosque "apanhar pássaros para o Menino" ou parte para uma festa e "trar-lhe-á biscoitos na volta", o que converge no texto - "O Menino de Maria / chama pai a S. José / que lhe trouxe sapatinhos /da feira de S. André". Num excurso rápido, a correlação sagrado / profano faz circular versos de uns para outros cantes como já notou J. Vasconcelos (id, p. 917) e destes para outros géneros, além fronteiras espalhados. 
CARVALHO, Maria José Albarran. Inserção do profano no sagrado - a adoração do menino num corpus de peças de Cante.

Trocando os "nomes" pelos "verbos", o Menino enamora-se da cigana do Egipto (Anexo 2), o que se comenta "olha a dita da cigana9 / que lindo amor que ela tem"; zanga-se com as moças e queixa-se "Deram-me as moças na fonte / já não quero lá ir mais" - motivo semelhante aos do S. João, na literatura consultada; chora e treme; mas sofre e salva; é adorado, ainda que... roubado... (Anexo 3). Para salvação do ladrão, explique-se, se continua permitida uma curta excursão por predicadores. O menino procede a intercâmbios. Aceita, admite-o um texto, prendas, para reservar "um lugarinho no céu" ao ofertante. Finalmente, apela-se à "Senhora lá do alto" para ver "o Deus Menino nos braços da Virgem Pura", num desdobramento da entidade intermediária do profano perante o sagrado. Na verdade, chama-se a "Senhora lá do alto" para vir ver o palpável, concreto, da imagem de uma Virgem com o Menino, que perde, por conseguinte, a função de representante da própria Nossa Senhora, visualizada em escultura.

Uma conclusão imediata faz sobressair a prevalência de N comuns contextualizadores de outros, igualmente comuns, apenas como

9 Numa nova digressão, o tema do cigano expande-se pelo Alentejo, da margem esquerda à direita, até Odemira. M. Delgado (1980, p. 79) inclui modas, v.g.: i) "cigano, lindo cigano / cigano, meu lindo bem / já lá vai cigano preso / sem roubar nada a ninguém ....", mas tinha achado uma corda que "na ponta tinha a mula" ...; ii) "Sou cigano, sou cigano / Sou cigano, mas não o nego / Eu sou o maior cigano / Que anda no altar do pego" (releiase a nota $1 . .$.$) . Em S. Brás de Alportel, vizinho do Alentejo, o povo vai cantar as Janeiras$ diante dos presépios e, segundo J. Vasconcelos (fs1982vVIII, p.84), "nessa espécie de teatro", canta-se: "Sou cigano do Egipto, / O meu destino é roubar: / Hei-de roubar Deus Menino Prà minh'alma se salvar...". No Alto Alentejo, foi recolhida a quadra "A cigana do Ingito / Caminha para Belém / Dar as graças ao menino / E à Virgem o parabém" (Alandroal), conforme J. Vasconcelos (1958,vIV, p.416). A identidade é notória... A este respeito, anote-se, em sintonia ainda com J. Vasconcelos (1938vVII,II, p.1270), que, nas "Constituições Episcopais portuguesas do século XVII" se definem como graves pecadores "os que pedem aos Egípcios" que lhes leiam a sua sorte, e, consoante a Ethnographia Portuguesa de F. A. Coelho, Egípcios significa ciganos, étimo das designações nas línguas europeias, no seu entender, contestado por J. P. Machado (Ed1977,vVII) defensor do étimo grego athínganos (em quem se não deve tocar). Os especialistas que o esclareçam. Interessa aqui que, tradicionalmente, se atribuía uma origem egípcia aos ciganos, em meios mais e menos literatos, consciência de origens que a redundância "cigano do Egipto" mostra estar a decair a partir de cerca do século XVIII . 
instanciadores, próximos da realidade humana e concreta, de uma realidade abstracta e complexa - o sagrado. As predicações, também examinadas, veiculam propriedades ou relações atribuíveis, portanto, aos argumentos anteriormente caracterizados, i.e., $\mathrm{N}$ comuns denotadores do quotidiano dos homens. Neste sentido, não ocorrem em $\mathrm{F}$ de espécie, pois a ausência de $\mathrm{N}$ de espécie e o tempo pretérito perfeito - relegam para situações contingentes a respectiva referência.

A Virgem referida por Mãe, por Maria, desce ao popular, ao N comum, à mãe humana ${ }^{10}$, como sua representante tal como o Menino aparece nas realidades de qualquer menino. A própria nudez do Menino, purificação, plenitude do sagrado, alia a distância do divino ao povo, na reprodução do modelo divino da pobreza, tão cruamente conhecida dos (re)produtores / executores destes cantes sagrados. É o nosso mundo, onde nasce o Menino, para sofrer como quem canta, e salvar, sobretudo, quem do mesmo modo vive. Nessa conexão se projecta o sonho, a evasão do real, a esperança de um campesinato na miséria, que se sente desenhado na pobreza evangélica. Tópico para a sociologia das religiões, a redução do sagrado ao quotidiano camponês fica apenas anotada.

Nos espécimes examinados, são evidentes casos de intertextualidade com o cancioneiro de assunto religioso. Vejam-se motivos como os que se seguem: i) expressões nominais: três palavras, meia-noite, bordado de prata fina, rosa, olhos, pão, espiga, ii) frases: "antes de o galo cantar"; "caminhando vai José, caminhando vai Maria"; "tanto caminhavam de noite como caminhavam de dia"; "está uma mulher cosendo"; "está fazendo a camisinha"; "já toda a gente dormia", "só estava uma porta aberta”: "onde o gado recolhia”, etc. Aliás, o número, a hora, a actividade da mulher, o bordado e os olhos são comuns ao cancioneiro profano.

10 J. Vasconcelos (1938, v VII, II, p.811) defende que a mãe se assimila "à Virgem Maria, que também teve um filho", como a criancinha se "assimila a Jesus, que também foi menino", pois "o povo achou semelhança entre a infância do Menino - Deus e a dos filhos dos homens". 
CARVALHO, Maria José Albarran. Inserção do profano no sagrado - a adoração do menino num corpus de peças de Cante.

Muitos destes motivos são recorrentes noutros cânticos sagrados recolhidos pelo país. É curioso anotar que a frase "pastorinhos de $o$ bom dia / deitai o gado à verdura" ocorre noutra versão, "pastorinhos de o bom dia / aqui está Santa Maria”, no cancioneiro da Beira-Baixa, recolhido por F. Lopes Graça - O romance da andorinha graciosa ouvido ao coro da Universidade Nova de Lisboa, o que prova uma recorrência entre cânticos sagrados.

Particulariza o território baixo alentejano a sua combinatória, numa recursividade por circulação de versos, de fecunda intertextualidade, produtora de novas peças, que por vezes não ultrapassam a mera adição / encaixe de excertos de outras. Enriquecimento ${ }^{11}$, com muita cor local, revela-se bem idêntico à produtiva repetição de versões na transmissão oral de fixação memorialística, do romanceiro.

Prossegue-se a análise linguística repetindo que, se no léxico nominal intervém notória quantidade de itens designadores do profano, no verbal o mesmo sucede, para ser acrescentado, finalmente, o comentário de mais itens lexicais nominais. Observa-se tão somente que o anacronismo igreja (Anexo 4) serve a apropriação do sagrado pelo profano, por constituir a designação popularmente mais conhecida de um espaço sagrado e, além disso, constituir forma de avizinhamento do divino. A água, constituinte significativo entre o acervo lexical sagrado, símbolo de purificação, integra o mar, onde Jesus aparece sobre uma pedra, outro $\mathrm{N}$ indutor do sagrado. As fitas em oferenda, eventualmente à imagem do menino em chapéu - costume comum nas imagens, de roca ou não, do Menino Jesus de pé, disseminadas no século XVIII merecem indicação suplementar. O termo fita (Anexo 5) prevalece sobre a alternativa galão (Anexo 5 e 6), índice de intenção meramente decorativa. É que a fita tem a ver com práticas mágicas primitivas de ligação ao sobrenatural, à morte, ao sagrado. J. Vasconcelos (1938, p. 118) noticia este tópico em Foz Coa, em versão profana, v.g.: "ó meu amor, quem de deu / a fita para o chapéu, / que t’a queria eu dar / azulinha da cor do

Saliente-se a analogia com a inserção de cantigas em modas, ou sequências destes conjuntos, tornados subconjuntos de novas peças. Na intertextualidade se repercute o temário religioso do cancioneiro / romanceiro português. 
céu?". A. Marvão (1955, p. 80) atesta-o numa moda que aponta como construída da cantiga beirã Adeus Vila de Idanha: "Adeus cemitério novo / de roda tudo são fitas....". J. Vasconcelos (fs1982vVIII, p. 332 ss) descreve, nas festas do Espírito Santo, nos Açores, a tradição de erguer um pau com fitas encimado por uma pombinha. Julgam-se motivos recorrentes no país inteiro. Os cueirinhos, hoje em desuso, evocam o vestuário infantil do século XV ao XIX (J. P. Machado, 3. ed. 1977 v II, p. 262). Para terminar, o léxico examinado pouco reflecte a nobreza e a riqueza: uma menção a um palácio real e outra ao bordado de prata fina e a botanitos de cristal.

Passando a outros elementos de teor localista - morfológico, fonológico, etc. - eles reafirmam, acrescidos à referência nominal e seus predicadores, a apropriação do sagrado, já que o aproximam do crente, da sua realidade oral quotidiana. Pelo menos, conhecida por perda da distante atemporalidade do divino, e, particularmente, da língua latina usada nas celebrações, ou, também, de um português culto com o qual nunca se privou.

Como sintoma de regionalismo ao nível morfológico, surgem as formas: botanitos, de . 0 . Na primeira verifica-se a preservação do -n(como é sabido, em posição intervocálica) decorrente de influência moçárabe. Na segunda verifica-se uma ausência de contracção - assinalada (.) - da preposição DE com o artigo definido, frequente na região - porém detectada, também, na zona de Idanha-a-Velha - de que resultam leituras divergentes, hiática e glidizada, com óbvia reestruturação por inserção silábica naquela.

Ao nível fonológico encontrou-se: *sacláiro, "paláiço (metáteses por atracção da tónica); "tremera, "valera e *reala, *Natala (reestruturação silábica com -a paragógico, circunscrita a Serpa e Baleizão), fenómeno menos produtivo que o-[i] / -[i] de Jose[i], cristal[i], tremer[i], valer[i], roubar[i] , cantar[i] . A ausência do [r], por preferência pela consoante lateral e coronal [l], em *sacláiro constitui fenómeno vulgar. A articulação igr[e]ja integra a identidade, em termos de manifestação fonológica, do alentejano, ao lado de b[ẽ], d[e]tado, m[e] - três casos lapidares de redução do ditongo a vogal nasal / oral. Trag[õ] é arcaizante. J[e]sus é 
CARVALHO, Maria José Albarran. Inserção do profano no sagrado - a adoração do menino num corpus de peças de Cante.

vulgar em certos desempenhos socialmente conotados com fraca escolaridade. O desempenho oral parco nas ligações próprias da modalidade, v.g.: uma . estrela"; "reis do . Oriente", deve relacionar-se com a entoação, nada estudada, tanto do dialecto regional quanto dos restantes. A nível sintáctico notaram-se: i) problemas de concordância, v.g.: "entrai pastorinho.... irás ver; ii) usos da construção aspectual durativa estar/ir + gerúndio, v.g.: "está uma mulher cosendo"; iii) sequências temporais com gerúndio regido pela preposição EM v.g.: "para o Deus Menino em nascendo".

A proximidade do sagrado nascimento atinge ponto tão geral, que se encontram excertos, possivelmente destes Cantes em canções de embalo ${ }^{12}$ autóctones, espalhadas pelas famílias de todo o território e não só, v.g.: "Durma já bem / ó meu menino / que a sua mãe já vem / foi lavar os cueirinhos / à fontinha de Belém”; "Joséi embala o Menino / Que a Senhora logo vem/Foi laval-os cueirinhos / À fontinha de Belém” in A Tradição (2. ed. 1982:1ª 1899, p.7).

Esclareça-se, também, numa análise transfrásica, que diálogos realistas, do dia-a-dia, com o Menino, como o da cigana, o dos artigos da feira de Santo André, ou o da oferta da fita, de leite, não são estranhos ao teor de outros exemplos de inserção do profano no sagrado ${ }^{13}$. Veja-se a seguinte versão de Bragança (J. Vasconcelos,1960, p.323) de um travar de razões entre Santa Maria Madalena e a Virgem Pura, já

12 J. Vasconcelos (1958 vl, p.811) considera que o povo, estabelecendo analogias entre a infância de Jesus e as crianças dos homens, reanalisa as canções específicas destas, adaptando-as àquela, movimento que implica o inverso e, assim, "as poesias de carácter divino, correlacionadas com a mística fonte de Belém, tornaram-se meramente profanas". Em Valpaços, Moncorvo, Fornos de Algodres, Foz Coa, Alandroal etc. (id, 825-31) recolheram-se versos semelhantes na forma, léxico e conteúdo, v.g.: "Embala, José, embala / que a Senhora logo vem / foi lavar os cueirinhos ....; Rola, rola / Cala,cala meu menino / ca mãezinha logo vem / foi lavar os cueiros ....; O meu menino é d' ouro/....e hei-de dá-lo à Virgem / enquanto for pequenino".

13 Ainda J. Vasconcelos (1938, p.860-4) identifica uma "assimilação" que o povo "estabelece entre a sacra família e a sua própria (família)" e aduz profusos exemplos de motivos, versos convergentes na interacção em apreço, v.g.: “....descalcinho sem chapeú / que é do vosso sapatinho?"; "Oh! Dai-lhe leite / ao Deus Menino / Oh! Dai-lhe leite / que é pequenino" (Adeganha). 
intermediária de Jesus Cristo: "Eu bem vi 'star Madalena - fazendo sua oração, / Pedindo à Virgem Pura - que lhe desse a salvação. / Eu bem vi 'star Madalena - ao pé da cruz ajoelhada, / Consid'rando nos martírios - que Jesus passava. / - Tudo deixastes a Pedro, - que três vezes vos negava! / - Cala, cala, Madalena, - que não ficas deserdada! / Veio um anjo do Céu, - Nosso Senhor o mandava: / - Vem para o Céu, Madalena, - que tu de Deus és chamada; / Vem a dar contas a Deus - da tua vida passada. / - El'as contas boas são, - mas a vida era mui mala! / - Vem para o Céu, Madanela, - que já 'stás arrependida./ Senta-t’à sua mão direita, - que és das suas escolhida”. (Rebordainhos,1874).

A própria sequência apelativa "Entrai pastores, entrai”, aparentemente explicit / incipit de variante serpense de cante sagrado (rever Anexo 4), que ocorre também em explicit de variante da Aldeia Nova de S. Bento (Anexo 7), entre outras, é atestada em Vinhais, por F. Martins (1987, p.186) e por T. Braga, em Penafiel (1867, p.154). J. Vasconcelos (fs1982vVIII:63, p.80;82) demonstra idêntica apertada intertextualidade em três variantes distantes: I) Ilha das Flores "Entrai, pastores entrai / Por este portal sagrado, / Vinde ver o Deus menino / Entre palhinhas deitado" - se calhar a circulação fez-se de cá para lá, pois o Alentejo participou no povoamento do arquipélago; ii) Lamego "Entrai pr'aí, pastorinhos, / Por esse portal sagrado, / Vinde ver o Deus Menino / Numas palhinhas deitado...."; iii) Cinfães "O menino está na neve / E a neve o faz tremer: / Ó meu Menino J[e] $]$ sus / Quem vos pudera valer! / Entrai, pastores, entrai / Por esse portal sagrado: / Lá verás 'star o Menino / $\mathrm{N} \sim$ ũas palhinhas deitado....”. Realça-se a sucessão de dois conjuntos de versos comuns no cante sagrado - "entrai pastores" e "o Menino na neve" (Anexo 8), em abonação de uma linha, também nacional, de apropriação do sagrado pelo profano, na qual se insere a alentejana, sendo ambas pertença de uma tendência cultural do homem na expressão da sua religiosidade. Não se pesquisou além fronteiras, mas esperam-se núcleos de recorrência.

Outra sequência, a da adoração dos pastores / reis, v.g.: "cada um de / qual por sua vez”, surge, de novo, em F. Martins (1987, p.288) e em J. Vasconcelos (1982 vVIII, p.I, p.71), ambas no Norte do país. A oferta 
CARVALHO, Maria José Albarran. Inserção do profano no sagrado - a adoração do menino num corpus de peças de Cante.

de uma gaiola, feita por S. José, é atestada no Vimioso (F. Martins, 2. ed. 1997, p.160), tal como se testemunham significados variados das fitas, na dança das fitas, em Vinhais (id,1987, p.390 ss).

T. Braga (1867, p.52) afirma que os "cantares populares da noite do Natal são o culto da infância, das esperanças que alimentam o seio que a amamenta”. Assim é vista a infância de Jesus até além fronteiras, porquanto motivos como a Virgem a lavar e S. José a estender roupa se recolheram em Itália (T. Braga, 1867, J. Vasconcelos, 1938).

A quotidianização do culto, como apropriação e assunção de maior religiosidade, entra em relação conversa, no Baixo Alentejo, comprovadamente, com a distanciação crítica de versos como a cantiga e as modas seguintes: "Dizem que Nossa Senhora / Certo dia no altar, / Quis morrer de inveja / Ao ver o teu lindo olhar...." (V. Santos, 1938, p.99); "A Senhora lá do Monte / Tem um moinho na mão, / Para moer as mentiras / Das beatas que lá vão”. (id, p.97); “....Visitou o oratório, / Para beijar a santinha (bis). / Para ver se é santa ou não" (M. Delgado, 1980, p.92). Nesta fase da pesquisa não se dispõe de dados do resto do país.

A geografia considerada, a partir da margem esquerda do Guadiana, foi uma opção metodológica ditada pela comodidade. É óbvio que os mesmos temas se repetem à direita do Guadiana e, como se viu, até no restante território nacional e europeu - mais não se pesquisou... Se forem confirmadas outras afinidades com o romanceiro peninsular, seguramente se repercute o temário dentro e fora do contexto europeu. A tradicionalidade não é tão regional como aparenta. De facto, a investigação realizada não o prova. A recorrência de temas, motivos, símbolos, etc. aponta noutra direcção. Perduram variantes mais antigas em zonas isoladas, que as preservaram, mesmo não sendo delas originárias, quem sabe (nem a presente busca queria encontrar as origens...), justamente pelo seu isolamento.

A propósito da tradicionalização de cantes sagrados, um breve apontamento quanto à sua construção poética. A rima é maioritariamente toante nas 100 variantes, o que não está representado nos anexos, seleccionados para outros fins. As variantes de rima consonântica, curiosamente, oferecem identidade de toda a última palavra, por ve- 
zes de todo o verso (vide versão de Vila Verde de Ficalho), o que pressupõe serem mais recentes. No tocante à métrica, predomina o verso curto (ai Meu Menino), redondilha menor / maior de alguma irregularidade (quase todas as peças) - podendo, de qualquer modo, ser transformado, em dois hemistíquios, no verso longo preferido pelo Romanceiro, segundo os especialistas da área. É o verso típico da poética popular, mas o dialecto meridional impõe, no Alentejo, reestruturações silábicas com a adição de sílabas e a ausência de contracções atrás discriminadas.

\section{A ADORAÇÃO DO MENINO PELOS REIS MAGOS}

Passa-se, agora, à adoração pelos reis magos. Peças menos exemplificativas do significado dos designadores rígidos, $\mathrm{N}$ próprios, para a análise da profanização do sagrado, mas que, de algum modo também o fazendo pela referência nominal, constituem melhor ilustração da temática regional, conforme adiante se propõe, e, sobretudo, mostram formas de inserção de conteúdos profanos no universo sagrado, através de elementos discursivos, intertextuais - escritos/orais - e culturais, além de entrecruzarem, profanamente, subconjuntos do mesmo universo.

Mais marcadamente alentejanos parecem os textos Quais são os três cavalheiros ${ }^{14}$ (Anexo 9 e 10), verso que encima a quadra recorrente

14 O cotejo com outras formas de distribuição do item cavalheiro autoriza a sua interpretação como equivalente a cavaleiro = posição social. Em A Tradição,2 (2. ed. 1982, II-1902, p.42), naquele sentido, a propósito da práticas religiosas na região de Serpa, afirma-se que a assembleia de crentes, ao vir "o padre para o altar", diz em oração: "Deus te salve cavalleiro honrado / Que co'as armas de christo vens armado!....”. Na esteira deste contorno de ocorrência, M. Delgado (1980, p.79-80) inclui como moda de dança de roda a peça Ó condessa, ó condessinha, de estrutura idêntica à dos romances, cujo texto contém os versos: "Volta atrás, ó cavalheiro, / Se queres ser homem de bem, / Dou-te uma das minhas filhas, / Peço que me $a$ trates bem." Se a forma lexical difere - a segunda apresenta a mesma palatalização presente no título dos espécimes agora em apreciação - ambas oferecem uma leitura semântica única deste item lexical - a de homem com a posição social de cavaleiro, nobreza não titular e, justamente por ser menor, muito expandida pelo país. 
CARVALHO, Maria José Albarran. Inserção do profano no sagrado - a adoração do menino num corpus de peças de Cante.

em quase todas as 35 variantes pesquisadas, mais longas e mais curtas. De realçar é o facto de cerca de 15 respeitarem ao concelho de Serpa, eventualmente de freguesias originárias / preponderantes quanto à circulação do texto. Este enquadra-se num tópico usual do temário dos reis - a adoração dos reis magos. De todo o país concorrem variantes do tema mas, na literatura considerada - especialistas como J. Vasconcelos, T. Braga, F. Martins, J. Pires, F. Lopes-Graça, J. PintoCorreia, etc. -, apenas nas regiões meridionais se encontra a quadra habitualmente incipit do cante aos reis, muito embora em duas versões ocorra depois do incipit - Vila Verde de Ficalho (margem esquerda) e a de S. Miguinhas (1981 - margem direita). Numa só variante, a da Trindade, o incipit refere-se a "Três Marias" e não aos "Três cavalheiros". Umas versões situam-se além fronteiras baixo alentejanas, em Juromenha, Campo Maior e Elvas.

Ecos registados noutras partes do território respeitam aos versos "foram-no encontrar em Roma / revestido no altar", recorrentes, como motivo, em diversos romances de assunto religioso. Na actual fase da investigação nada mais se pode aduzir, permanecendo, até novos dados, a convicção do carácter mais autóctone deste elenco de variantes.

Aliada ao culto do nascimento de Deus Menino, a adoração dos reis magos sucede-lhe no calendário da liturgia cristã. É interessante verificar a sobreposição de dados da história da liturgia na matriz das diferentes versões:

- os três reis provêm do Oriente, vêm buscar Jesus, por via marítima (o centro do mundo cristão desloca-se da Palestina para o país dos produtores / executantes das peças de cante);

- Jesus Cristo é adorado pelos reis magos em Roma, que substitui Belém na larga maioria das versões, e, num só caso, a adoração localiza-se na Cova da Iria (Anexo 11), lugar do santuário de Fátima (ainda mais próximo no tempo e no espaço, o que valida a tendência identificada de se aproximar o sagrado do crente);

- a deslocação, maioritária, para Roma corresponde a uma realidade posterior à natividade, quando se cria a igreja e o papado, ali sediado, centro hierárquico e difusor do cristianismo no Ocidente; 
- Jesus Cristo está revestido / vestidinho (uma única versão) no altar, contemporâneo da "hóstia consagrada", da "missa nova" com o seu "missal" e a "comunhão", eventos ulteriores ao seu nascimento;

- S. João e S. Pedro - santos populares nacionais - e a Virgem (numa única versão) ajudam à missa, devendo o segundo "mudar o missal”, passo da celebração caído em desuso, costumeiro no tempo em que os sacerdotes oficiavam de costas para a assembleia e o missal mudava do lado da Epístola para o lado do Evangelho.

Aparecem vários outros motivos associáveis à tradicionalização, v.g.: "três cavalheiros"; "três mil almas de roda"; "perguntar por pousada"; "onde irão pousar / pernoitar"; "vêm adorar / buscar Deus": "por uma estrela guiados". A uniformidade das variantes e a sua menor quantidade fazem com que os exemplos de motivos discursivos sejam inferiores aos encontrados no anterior subtema.

Na referência nominal à entidade sagrada, numa análise lexical também realizada sobre as peças relativas à adoração dos pastores, predomina como primeira instanciação, na adoração dos reis, o N próprio Jesus (38), seguido por Jesus Cristo (7), Deus Menino (6), Menino Jesus e Messias (1). Quer dizer, ainda uma vez a prevalência do designador mais próximo do profano, o antropónimo Jesus, atribuível aos filhos(as) dos homens como primeiro nome. Nos $\mathrm{N}$ comuns, dá-se o preenchimento do espaço que priva com o sagrado, desconhecido, pelo nome igreja, local conhecido, onde se oficia a missa, deslocação paralela à de Belém para Roma, onde os textos situam o nascimento de Jesus e que é, a partir da alta Idade Média, a principal referência da hierarquia cristã.

Apesar dos referidos elementos recentes, predominam marcas de antiguidade: rima preferencialmente toante, verso curto de redondilha maior com certa irregularidade métrica; um léxico arcaizante - v.g.: buscar / perguntar na acepção de procurar, item com o qual comuta em diferentes variantes.

Enfoque linguístico mais minucioso, e abrangedor de diferentes componentes da gramática, pouco acrescenta à análise supra levada a cabo para as variantes do subtema da adoração dos pastores, pois idênticas são as manifestações dialectais, sociais e arcaizantes. Mor- 
CARVALHO, Maria José Albarran. Inserção do profano no sagrado - a adoração do menino num corpus de peças de Cante.

fologicamente atesta-se a mesma falta de contracção da preposição com o artigo, v.g.: "de . o Oriente". Em termos fonológicos, manifesta-se a redução de ditongos a vogal oral / nasal, definidora do português meridional, ao lado da preservação de vogais nasais que não desenvolveram ditongo, traço vernacular, v.g.: respectivamente: i) p[o]sada, caminhav[õ], pergunt[ã], faz[ẽ], [ẽ]; ii) s[õ]. A seu lado o-[i]/-[i] e -[e] paragógico como reforço e reestruturação silábica de: aond[i], Orient[i], no primeiro caso

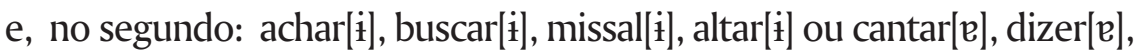

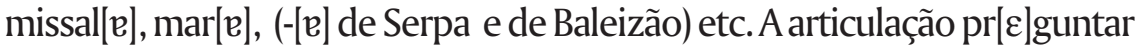
revela-se marca sociodialectal disseminada pelo país, em expansão comum: i) à instabilidade de -[i]/[i] pretónicos, S[i]nhora, J[e]sus; ii) à palatalização de cava[K]eiro; iii) à assimilação por nasalização reestruturante da ordem consoante - vogal de são-nos.

São de notar testemunhos da abordada circulação de versos que se ilustra apenas com: "Qualquer filho d'homem nobre/ numas palhinhas deitado"; "Menino tão pequenino"; "vamos cantar o rei". Contudo, as variantes constituem um todo muito coeso, não viabilizando divisões por subtemas, se exceptuarmos a questão das únicas três que aceitam os motivos acima listados.

Na verdade, as restantes podem apresentar um texto médio, curto ou longo, i.e., total ou com omissões do arquétipo textual, pois neles apenas a toponímia, as instanciações do sagrado se alteram, v.g.: com a introdução de terceiro intermediário, a Virgem, junto de $S$. João e $S$. Pedro. A uniformidade das variantes impõe uma disseminação pouco ampla, menos antiga do que a tradição do cancioneiro que remonta a tempos medievais. O texto poderá remontar a eventos pós-renascentistas, como as representações e vilancicos de Natal, muito provavelmente dos séculos XVII - XVIII, época da proliferação das imagens de roca - caso a presente hipótese de leitura se demonstre -, vestidas, como a deste Jesus "revestido no altar". Põe-se de lado o arcaísmo, visto que re+vestido ${ }^{15}=$ vestido foi introduzido no século XIII, conforme J.P. Machado (1977v VII).

15 O termo aparece num responso, recolhido por F. Martins (2. ed. 1997, p.43), no sentido de vestido, paramentado: "valha-me o santo nome de Jesus / e a sua santíssima cruz, / e os três padres revestidos....”. J. Vasconcelos (fs1982, v VIII, p.80;82) também abona esta 
De facto, o texto concentra muita informação litúrgica, ainda que desarticulada e com sobreposição da adoração dos reis magos ao culto das almas do purgatório - iniciado cerca do século XVI - acentuado nas festividades da Ressurreição, festa distinta mas confundida com a adoração dos reis nos espécimes de cante examinados. Temporal e espacialmente relegado para o mítico, esboça-se um imaginário cristão em que os reis magos: i) são cavaleiros - baixa posição social da nobreza, porém respeitada e conhecida nos ambientes rurais mais isolados; ii) vêm de longe - d'além mar; iii) adoram o Deus Menino em Roma, revestido no altar, pronto a salvar milhares de almas, que comungam numa missa acolitada por santos populares e, numa versão, pela Virgem Maria.

Este arquétipo dos espécimes vistos pressupõe, completando informação atrás já fornecida, um celebrante virado para o altar, de costas para o povo, e o ajudante a mudar o missal - cerimonial iniciado no século XVI e mantido até aos anos 60 (J. Mattoso, comunicação pessoal, 1998). Alguns sintomas legitimam o diagnóstico, de datação mais recente (hipótese atrás advogada), lá pelo século XVIII - época áurea das imagens de roca, se foi esta a acepção de revestido, frequentes também no concelho de Serpa. De tal data, moderna, decorre a coesão textual detectada, pois os poemas, mais ou menos curtos, resistem bastante, insiste-se, à introdução de outros subtemas, comprovadamente raros, e da matriz não se encontrou notícia noutras regiões, excepto nas fronteiriças do Baixo Alentejo, não obstante o tema dos reis ser tão fecundo no país. Se bem que a investigação implicada pelo Projecto $O$ Cante não esteja concluída, viu-se a proliferação de recorrências respeitantes ao subtema da adoração dos pastores, partindo-se de um mesmo corpus e obra de especialistas, daqui parecendo lícito inferir que estes últimos textos são, por isso mesmo, mais antigos. Na linha inversa, as peças Os três cavalheiros remetem, pelo carácter fortemente uniformizado, para muito provável juventude na

circunstância de ocorrência, em sequência quase igual à das peças em análise: Jesus Cristo "revestido num autar" e "revestido no altar". Contrastando a distribuição do item, conclui-se que a interpretação é a proposta. 
CARVALHO, Maria José Albarran. Inserção do profano no sagrado - a adoração do menino num corpus de peças de Cante.

sua produção, sem se invalidar o notório movimento de recorrências da temática sagrada, radicado em fontes medievais, paralelas ao cancioneiro e sempre de mão dada com o romanceiro de assunto religioso.

Detendo-se o presente estudo na variante, única, em que os três reis dão lugar às Três Marias, versão encontrada na Trindade, não muito longe da margem esquerda do Guadiana (Anexo 12), chama-se a atenção para a realidade de haver réplicas deste incipit. Como exemplo, eis a segunda parte de uma oração a Santo António, publicada em 1927 por F. Martins (2. ed.1997, p.33): “....Lá se vão as três Marias / de noite pelo luar / em busca do Deus Menino / sin o poderem achar, / foram dar co' Ele a Roma / revestido ó altar; / missa nova quer dizer, / missa nova quer cantar"16.

J. Vasconcelos (fs1982, v VIII, p. 48, 70) noticia duas outras, uma a propósito da Janeiras (Guimarães) e outra ouvida nas festas do Espírito Santo (S. Martinho de Mouros) : i) "Onde vão nas três Marias / De noite, pelo lũar, / Em busca de Jesu-Cristo / Nunca o puderom achar; / Forõ dar cum Ele em Roma, / Revestido num autar, / Cum cálix de oiro na mão, / Missa nova quer cantar; / Três anjinhos a ajudar....”; ii) “ Lá vêm as três Marias, / Do monte, pelo luar, / A procurar Jesus Cristo, / Sem o poderem achar. / Foram dar com Ele em Roma, / Revestido no altar / E cálix de oiro na mão, / Missa nova quer cantar...."

A tradição cristã, baseada nos Evangelhos sinópticos, identifica estas Marias como Maria Madalena, Maria de Cléofas, mãe de Tiago (Lc e Mc), outra Maria (Mt) e Maria Salomé, mãe de João Evangelista (Mc). Só este último indica três Marias; nos restantes ou não perfazem este número, ou aparece uma Joana (Lc), ou nem sequer são referidas (Jo). Os textos, parcos, narram a ida destas mulheres ao túmulo, a au-

16 Neste contexto discursivo e sintáctico, propõe-se a leitura de "revestido" como sinónimo de "paramentado". O regime preposicional assim o parece determinar - tratando-se, assim, de uma aparição de Jesus Cristo paramentado de oficiante, vindo ao altar para a celebração da missa e não de uma imagem de roca colocada no altar, interpretação esta também discutível, como se viu. O critério preposicional é falível já que poderá decorrer de mera instabilidade no seu regime ou na tendência para ser preferida a preposição estática EM, em contexto de movimento. 
sência do corpo e a revelação da ressurreição. Do susto à necessidade da busca do Redentor oscilam as reaç̧ões.

O maravilhoso cristão cria a lenda, em conformidade com L. Réau (1958tIII,II): Maria de Cléofas e Maria Salomé - meias irmãs da Virgem, numa sobrevalorização da santidade do parentesco - deixaram a Palestina, por mar, acompanhadas por Maria Madalena, Marta e Lázaro e desembarcaram em Marselha, com uma servente. Procuravam o Redentor. Ali permanecem e ficam enterradas no delta do Rhône. Sobre o túmulo ergueu-se a igreja de Nossa Senhora do Mar. O culto desenvolve-se no século XV, sobretudo na Provença. São conhecidos os seus estreitos laços culturais com o ocidente peninsular, desde a Idade Média - sobretudo nos séculos XII-XIV.

Nas procissões do Senhor dos Passos, segundo J. Vasconcelos (fs1982, p.206) as Três Marias seguem atrás do andor, por exemplo em Ponte da Barca, num relato de 1860 . Tal presença demonstra o vigor do tema na religiosidade do povo português.

Também se desenvolveu um culto na Boémia. Salienta-se o vigor de peregrinações a Camargue, especialmente de boémios e ciganos, que "veneram particularmente a serva Sara" (id, p.889) e disseminam tradições pela sua forte mobilidade.

Em França, bohémiens comuta com tziganes, na via de J. Vasconcelos (1958, vIV, p.352), autor que advoga como pertinente a hipótese de uma origem egípcia dos ciganos, entre as mais próximas, (id) e a da sua vinda para Portugal no século XV - data de 1510 a primeira referência textual - (id, p.351). Segundo aquele autor, entram de Espanha, tendo chegado à Catalunha em 1447 - cujos laços com a Provença remontam a larga história que ultrapassa os de Portugal -, pelo Alentejo, "em que sempre preferiram viver” desde então (id, p.352), listando-o, aquele autor, entre as localizações documentalmente preferidas até aos séculos XVI-XVII (id, p.355-6) - que afirma manterem-se à data da sua investigação (ib) - e onde deixam topónimos como vestígio (ib).

Aponta ainda, o plurifacetado etnólogo, a respectiva autoculpabilização por não terem dado "hospitalidade à Virgem quando peregrinava pelo Egipto" (id, p.351), e a sua forte religiosidade cristã. Lembre- 
CARVALHO, Maria José Albarran. Inserção do profano no sagrado - a adoração do menino num corpus de peças de Cante.

se a comunidade cristã cigana desde sempre ligada a Serpa e Moura / Ourique, Panóias e Cuba, à esquerda e à direita do Guadiana, no Baixo Alentejo, além da presença do cigano no cante profano e sagrado, nomeadamente nos autos da Natividade acima descritos. Todo este historial de dados coincide no fortalecimento do eventual papel cultural da comunidade cigana de então na transmissão / fixação, conjuntamente, dos temas das Três Marias / Três Cavalheiros, pelos séculos XVII-XVIII, porquanto nessa época, além da presença do cigano(a) nos autos de Natal, se verifica que: i) floresce a presença cigana no Alentejo - reverenciam um "conde" em Elvas no século XVII; ii) são ainda designados por egípcios, até aos séculos XVI-XVII, tempo da introdução dos termos gregos, grecianos, na literatura e documentação histórica, em frequente comutação com o item, já então mais fecundo, de $\operatorname{ciganos}^{17}$ (Farsa das Ciganas, 1521, de G. Vicente; iii) se espalham as imagens de roca.

Em Santiago de Compostela há uma igreja dedicada a uma das três, Maria Salomé, sendo bem vivo o ímpeto das peregrinações anuais, inclusive hoje em dia, o que justifica atestações do tema no norte de Portugal, onde tem sido vulgar ir-se a Santiago.

No texto em exame, as três Marias partem em busca do Deus Menino, símbolo principal da espiritualidade, do sagrado, da salvação e não encarado como mera instanciação do divino na sua encarnação em Jesus, o recém - nascido de Belém, temporalmente incompatível com Maria Madalena, Maria de Cléofas e Maria Salomé. Procuram o Redentor, o Salvador sob a capa da instanciação do Deus Menino. É uma sobreposição de diferentes instanciações do sagrado - o mesmo através do diverso. Salta-se da promessa de redenção, anunciada na natividade, para a esperança resultante da ressurreição pouco anterior à partida delas - junta-se o Natal à Ressurreição, eliminando-se a escalada intermediária. Quer dizer, sendo objectivo do nascimento a redenção, o imaginário popular vê-os sobrepostos, como se a quinzena que vai do dia de

17 A redundância decorrente de, num mesmo texto, serem referidos por ciganos e do Egipto, prova a perda de consciência da origem geográfica atribuída, e mais antiga designação, ou instabilidade na nova nomeação, aqui se defendendo esta última eventualidade. Qualquer das hipóteses, contudo, confina a hesitação ao período entre o século XVII e o XVIII. 
Natal ao dia de Reis possibilitasse todo o percurso, tanto mais que delimita as duas tradições de cante objectos da presente pesquisa - a adoração dos pastores e, duas semanas depois, a dos reis magos, com as Janeiras, de origem pagã - a evitar pela igreja - a mediá-las.

É em Roma, em posteriores aditamentos à lenda, que encontram o "Deus Menino", vestido no altar, em hipotética ambivalência de imagem de roca, personificação de Jesus oficiante nos preparativos da celebração. O imaginário mítico cristão oferece maior consistência neste texto, pois as três Marias vão (da Palestina) para Roma, sede da igreja em cujo edifício se encontra a imagem de Cristo - e do sumo pontífice, o primeiro dos quais, na hierarquia dos Apóstolos, foi S. Pedro. Após este momento inicial, a tradição interpreta Jesus celebrante como imagem vestida - cerca dos séculos XVII-XVIII. Acrescentam-se, na versão alentejana, os santos populares a acolitar o celebrante Deus Menino. Exclui-se a referência temporal do texto de Vinhais "de noite pelo luar", evocadora do romanceiro, tal como a espacial "que fazem sombra no mar". As três Marias comutam com os três cavalheiros e eis uma das peças de cante sagrado mais divulgadas na margem esquerda do Guadiana.

Crê-se que as variantes mais antigas são as das três Marias, ulteriormente alteradas em região menos assistida por sacerdotes do que o Norte do país, e onde, consequentemente, é despoletado um maravilhoso cristão mais criativamente solto de fontes bíblicas e litúrgicas. Teria a comunidade cigana determinado a difusão do texto das três Marias? Óptimos transmissores de textos de fixação memorialística e, comprovadamente, radicados na região nos séculos aqui referidos, são candidatos privilegiados, entre mais, a uma acção difusora que, seguramente, conseguiriam garantir. Na escassez de estudos sobre as relações culturais dos ciganos com outras comunidades tal como sobre a divulgação do tema As Três Marias, nada se pode afirmar de definitivo.

Largamente, na verdade, se demonstrou que o Cante sagrado oferece vasta panóplia de $\mathrm{N}$ concretos referentes do $\mathrm{N}$ próprio Deus $\mathrm{N}$ de objecto abstracto de alta complexidade conceptual - tal como de fases, manifestadoras do sagrado no mundo temporal dos homens inserção do profano no sagrado que é corroborada por predicadores, 
CARVALHO, Maria José Albarran. Inserção do profano no sagrado - a adoração do menino num corpus de peças de Cante.

por desempenhos dialectais, pela intertextualidade com outros poemas e peças musicais de temática religiosa.

Facto é, ainda, que a variante Quais são os três cavalheiros não foi encontrada, nesta fase da investigação, em nenhuma outra região fora do Alentejo. Caso haja testemunhos, em número significativo, noutras regiões, ponderar-se-á noutro sentido.

Certo do mesmo modo é que os tópicos observados, só por si, provam uma transversalidade do cante sagrado / profano aos currículos de áreas como a Música, a Linguística e a Literatura. Na primeira, envolvem-se variadas disciplinas; na segunda: Linguística Portuguesa, Língua Portuguesa, Análise de Texto; na terceira: Literatura Tradicional, Literatura Portuguesa. Conteúdos de Sociologia das Religiões e de Antropologia Religiosa são igualmente abordados, para citar apenas algumas áreas do saber. Portanto, o Projecto em curso tem larga vida pela frente.

\section{OBSERVAÇÃO:}

O Alfabeto Fonético Internacional marca realizações ouvidas, em transcrições do próprio Projecto; itálicos e aspas assinalam, respectivamente, constituinte(s) ou sua sequência, quando remetem para texto escrito, recolhido pelo Projecto ou não, com preservação de ortografias no segundo caso - à excepção de casos que dificultariam a leitura.

\section{ANEXOS:}

A selecção de textos pretende ilustrar a referência nominal, outros tópicos linguísticos, e temas / subtemas da Adoração do Menino, 
de forma exequível, não atendendo, por conseguinte, a nenhuma outra representatividade de ordem linguística. Por razões de comodidade, optou-se pela atribuição de prioridade à margem esquerda do Guadiana, no nível do Projecto, região mais considerada no corpus do subgrupo em que se integra a autora.

ó Meu Menino Jesus (bis)

ó Meu Menino tão belo

logo havias de nascer

ao rigor do caramelo

ó Meu Menino Jesus

não querias Menino ser

ao rigor do caramelo

a neve te faz tremer (bis)

dá-me o teu Menino

não dou não dou não dou

dá-me o teu Menino

vai à missa que eu lá vou

2.

e o Menino . está na neve

e a neve . O faz tremer[i]

Deus Menino . em água molhado

$\mathrm{Qu}[\mathrm{e}]$ te pudesse valer

a roseira do sacrário dá boa rama

já os anjos colhem rosas na tribuna

quem me dera colher uma

namorou-s[i] . o Deus Menino

de . uma cigana . em Belém

e olha a dita da cigana

o lindo . amor que tem

\author{
Menino da Senhora \\ chama pai a S. José \\ que lhe trouxe uns sapatinhos \\ da feira de Santo André (bis) \\ o Menino chora chora \\ chora pelos sapatinhos \\ haja quem lhe dê as solas \\ eu the darei os saltinhos (bis) \\ dá-me o teu Menino etc \\ (cante?) \\ Ventos do Sul - 1996 (CD TOP) transc MJA 97 | \\ vers JM 98
}

3.

sou cigana do Egipto

o meu destin $[\varepsilon]$ roubar[i]

[e] -de roubar Deus Menino

p'r a minh[a]lma se salvar[e]

sou cigana do Egipto etc.

Baleizão, rec A. Cartageno/transc MJA 97/vers JM 98

Aldeia Nova de S. Bento, rec A. Cartageno / transc MJA 97/vers JM 98 
CARVALHO, Maria José Albarran. Inserção do profano no sagrado - a adoração do menino num corpus de peças de Cante.

4. (entre parênteses registam-se variantes tex- 5 . tuais)

Eu hei-de dar ò Menino

(entre) à porta da . igr[e]já Ai um galão par' ò chapéu (rep ambos)

está uma

'Ambém ele m’há-de da

está uma mulher cosendo

Ai um lugarinho no céu (rep ambos)

está fazendo .a(s) camisinha(s)

Vila Verde de Ficalho, Momentos Vocais (1980),

$\mathrm{p}[\mathrm{\jmath}]$ Deus Menin[ẽ] nascendo

J. Nazaré, Lisboa, INCM

entrai pastorinhos . entrai

por . este portal sagrado

vinde ver . o Deus Menino

entr' as palhinhas d[e]tado

Serpa, rec. A. Cartageno / transc MJA 97 / vers

JM 98

6.

eu hei-de dar (o,ao) Menino

[i] uma fita

uma fita pr[0] chapéu

e t [õ]b[êj]

Ele me há-de dar[rer]

E um lugar

Um lugarinho no céu

7.

Menino [i]stá na neve

E a neve . o faz tremer

E a neve . o faz tremer

Menino Deus da minh' alma

Quem te pudesse valer

Menino Deus da minh' alma

Quem te pudesse valer

Entrai pastores . entrai

Por esse portal sagrado

Rec. A. Cartageno/transc MJA 97/ vers JM 98

Vind[i] adorar o Menino

Numas palhinhas deitado

Vind' adorar o Menino

Numas palhinhas deitado

Rec. Corais Religiosos Alentejanos 1980/trans MJA 97/vers JM98

8.

Menino [i]stá na neve

Meu Menino da minh' alma

a neve

a neve. $\mathrm{O}$ faz ai tremer[i]

Qu[ẽ] Te pu

$\mathrm{Qu}[\mathrm{e}]$ te pudera valer[i]

Meu Menino da

o Menino' [i] stá na neve

da minh' alma

a neve

qu[ẽ] te pu

a neve. $\mathrm{O}$ faz tremer[i]

$\mathrm{qu}[\mathrm{e}]$ te pudera valer[i]. 
Filologia e Lingüística Portuguesa, n. 3, p. 23-54, 1999.

qualquer filho d'hom [ẽj] pobre nasce nu

nasce numa boa cama

qualquer filho d'hom [ëj] pobre

nasce nu

nasce numa boa cama

só tu o Meu Menino

nascestes

nascestes numa cabana (bis)

9

(quais, Kai-) são nos três cava[ $[$ Kej]|ros que fazem

que fazem sombras no mar

são nos três [di] · [u], do.) oriente

que Jesus

que Jesus v[e्ej] buscar (bis)

não pergunt[õ] por poisada

nem aonde

nem aonde pernoitar (bis)

pergunt ([õ]/ -ão)por Deus Menino

$(\mathrm{e}, \mathrm{j})$ aond[i] o

(e,j) aond[i]. o ir[ $\tilde{e}]$ achar (bis)

foram-no achar em Roma

revestido

revestido no altar (bis)

com três mil almas de roda

todas para

todas para comungar (bis)

S[r̃ $]$ João ajuda ‘à missa

S[ $[\tilde{e}]$ Pedro

$S$ [ $\tilde{e}]$ Pedro mud" o missal

Serpa, rec A. Cartageno/ transc MJA 97/vers JM 98 lá no meio daquele mar[i]

[i] stá uma

[i ]stá uma pedra (x,j, toda) lavrada (bis)

Onde se sent' o Menino

Filho d[i] . a Vir

Filho da Virg[ẽ] Sagrada (bis)

Rec. Corais Polifónicos Alentejanos 1995 (IM)

a 3 / trans 97/ vers JM 98

10.

Qual são nos três cavaleiros

Que fazem que fazem sombra no mar.

Repete

São os três do Oriente

Que Jesus que Jesus vêm buscar.

Repete

Aldeia Nova de S. Bento

J.

Nazaré (1980) Momentos Vocais, Lisboa, INCM 
CARVALHO, Maria José Albarran. Inserção do profano no sagrado - a adoração do menino num corpus de peças de Cante.

11.

os trê ( [ [J]/j ) rei j do . [u] riente caminhav[õ] p'ra Cova d'Iria

for[õ] fazer uma jornada

e à $\operatorname{pr}[\varepsilon]$ cura $\mathrm{d}[\mathrm{i}]$. o Messia XXX

quais são os três cava[ $K$ Ke]ros

que faz[ẽ] sombra no mar[i]

$\mathrm{s}$ [ã] os três do . Orient[i]

que Jesus v[ẽ] buscar[i]

$\mathrm{n}[\tilde{\mathrm{e}}]$ pergunt[ã] por poisada

n[ẽ] ond[i]rão pernoitar[i]

p[re lgunt[õ] p[ru] J[i]sus Cristo

ond[i]rão pernoitar[i]

com três mil almas de roda

todas para . o consagrar $[\mathrm{i}]$

S[ã] João ajud'à missa

$\mathrm{S}[\tilde{e}]$ Pedro ajud [o] missa[i] $]$

E a Virg[ẽ] Nossa S[i]nhora

No[ze]judou . a mudar[i]

S. Miguinhas

Rec A. Cartageno / transc MJA / 97 vers JM98
12

além ve[zif] $(x, ?)$ as três Marias

todas três XXX

perguntam por Deus Menino

sem no poder[ẽ] achar[i]

foram-no achar em Roma

revestido no altar[i]

missa nova quer dizer

missa nova quer cantar

S[õ] João ajud' à missa

São Pedro mud' o missa

Guerreiro, Trindade

Rec A. Cartageno / transc MJA 97 / vers JM 98

\section{AGRADECIMENTO}

Em primeiro lugar, ao Centro de Linguística da Universidade de Lisboa, consultor do Projecto $O$ Cante, e apoio da Escola Superior de Educação de Beja, via protocolo recentemente assinado. Em segundo lugar às docentes universitárias, velhas amigas destas lides, M. Ferreira, Faculdade de Letras de Lisboa, e A.C. Lopes, Faculdade de Letras de Coimbra, pelas valiosas opiniões críticas, precisões e correcções. Em terceiro lugar a J. Mattoso, historiador, J. Matos e A. Cartageno docentes daquela escola e membros do Projecto, pela rigorosa leitura, discussão da interpretação de dados e sucessiva reelaboração de versões até à final. Muito agradecida pela simpatia da docente Maria do Sameiro Pedro, da referida escola, na sua leitura e cuidadas sugestões. 
Filologia e Lingüística Portuguesa, n. 3, p. 23-54, 1999.

\section{BIBLIOGRAFIA}

BENVENISTE, E. (trad1969) Le Vocabulaire des institutions indo-européennes, v. 2. Pouvoir, Droit, Religion, Paris, Minuit

BRAGA, T. (1867) Poesia popular portugueza. Porto, Typ Lusitana

CARLSON, G. (1977) Reference to kinds in English. Tese de Doutoramento, Universidade de Massachusetts.

. (1982) Generic terms and generic sentences. Journal of Philosophical Logic, 11, p. $145-81$.

(1989) On the semantic composition of English generic sentences. In CHIERCHIA, G. et al (org.) Properties, types and mesning, v. II. New York, Kluwer, p. 167-92.

CARTAGENO, A. (1997) Recolha e recuperação do canto popular religioso. Comunicação ao Congresso Cante Alentejano, Casa do Alentejo, NERBE, Beja.

DELGADO, M. J. (1980) Subsídios para o cancioneiro popular do Baixo Alentejo. Lisboa, INIC. . (1970) O falar de Baleizão. Dis. de Lic. em Filologia Românica, FLL, Universidade de Lisboa.

ELIADE, M. (trad.1965) Le sacré et le profane. Paris, Gallimard.

FLINT, V. (1991) The rise of magig in early medieval Europe. New Jersey, Princeton University Press.

GOMES, S. (1998) Mosteiros de Cister. Comunicação ao Colóquio Cister - Espaços, Territórios, Paisagens, Mosteiro de Alcobaça, Alcobaça (16 Jun)

HEYER, G. (1988) Generic generalizations, discourse representation structures and knowledge. In HOEPELMAN, J. (org.) Representation and reasoning. Tubingen, Niemeyer.

LOPES, A. C. (1992) Aspectos da genericidade. Cadernos de Semântica, 6, p. 1-25 (Proj JNICT $91 \mathrm{FLL})$

(1993) Sobre a referência nominal genérica. Discursos, 4, p. 115-34.

MACHADO, J. P. (Ed. 1977) Dicionário etimológico da língua portuguesa. Lisboa, Livros Horizonte.

MARTINS, F. (1987) Folklore do concelho de Vinhais, v. 2. Vinhais, Câmara Municipal de Vinhais. . (2. ed. 1997) Folklore do concelho de Vinhais, v.1. Vinhais, Câmara Municipal de Vinhais.

MARVÃO, A. (1955) Cancioneiro alentejano. Beringel, Ed Franciscana. (ed. 1997) Estudos sobre o cante alentejano. Lisboa, INATEL.

MOENS, M.; STEEDMAN, M. (1988) Temporal ontology and temporal reference. Computational Linguistics, 14, p. 15-8.

NAZARÉ, J.R. (1980) Momentos vocais do Baixo Alentejo. Lisboa, INCM.

PERES, J. (1993) Esboço de uma semântica das estruturas nominais. Discursos, 4, p. 15-36.

VASCONCELOS, J. (1938) Opúsculos,v. VII,II. Lisboa, Imprensa Nacional de Lisboa. . (1958) Romanceiro português, v. I. Coimbra, Universidade de Coimbra. . (1960) Romanceiro português, v. II. Coimbra, Universidade de Coimbra. (fs1982) Etnografia portuguesa, v. VIII. Lisboa, Imprensa Nacional - Casa da Moeda. 
CARVALHO, Maria José Albarran. Inserção do profano no sagrado - a adoração do menino num corpus de peças de Cante.

Cânticos religiosos do Alentejo - audiograma (1980)

Corais polifónicos alentejanos (IM - 1995)

Recolha de A. Cartageno - audiogramas (1973-1984) - Escola Superior de Educação de Beja.

A Tradição,v. I,II (2. ed. 1982), Câmara Municipal de Serpa.

ABSTRACT: This article examines a corpus of variants of sacred "cante", by essentially resorting to semantic analysis. Na analysis of the noun references to the Holy Infant, in a world of beliefs assumed as Christian, contrasts instances of the divinity as a complex abstract object. By these reference processes the sacred entity and man are drawn closer. The former is, thus, hidden under more familiar entities, which occur, both at the sentence level and at the discourse level, in several elements - though they may have here a scarce treatment - such as: some verbs; lexical, morphological and phonological peculiarities; and other instances in the fields of sociolinguistics, and text analysis. All these converge to the appropriation of the sacred entity by man, as this article aims to demonstrate.

Keywords: semantic of nouns, semantics of verbs, prototypical characteristics, episodic characteristics, sentence level, discourse level. 